DOI: https://doi.org/10.15688/jvolsu4.2021.1.16

UDC 94(47+57)“1941/1945”:355.134

Submitted: 21.11.2019

LBC 63.3(2)622-35

Accepted: 18.03 .2020

\title{
AWARD PRODUCTION \\ IN THE RED ARMY DURING THE GREAT PATRIOTIC WAR (1941-1945)
}

\author{
Dmitry V. Shunyakov
}

Ural Federal University named after the first President of Russia B.N. Yeltsin, Yekaterinburg, Russian Federation

\begin{abstract}
Introduction. The article analyzes the experience of improving the system of award production in the Red Army during the Great Patriotic War. The author states that the award production at the time of the beginning of the war was unable to ensure mass awarding of soldiers. Methods and materials. Archival materials, published official statistics and scientific literature were used in the implementation of the research tasks. The study was conducted on the basis of the principles of historism, objectivity and systemacity. The need to process quantitative data led to the use of the statistical method. Results. In order to ensure the need of the active army to award, the leadership of the country in the Armed Forces introduced a single command and delegated the right to award to the military command, which awarded on the ground and submitted award documents through the people's commissariat for approval to the Presidium of the Supreme Soviet of the USSR. It is noted that in order to optimize the award production in units, formations, personal accounts were introduced, on which award marks and documents, as well as reporting on them were issued. Awarding bodies provided preparation of awarding documentation giving it to the commanding officer (commander) for approving, made rewarding of distinguished ones. Conclusions. It is noted that the measures taken to improve the award production brought it closer to the participants of fights, about $90 \%$ of all awards were made by the military command. It is shown that the awarding of military personnel led to the growth of their professional skills through personal interest in the results of combat activities, which was one of the factors of victory in the war.
\end{abstract}

Key words: USSR, Great Patriotic War, People's Commissar of Defense, Red Army, award production.

Citation. Shunyakov D.V. Award Production in the Red Army During the Great Patriotic War (1941-1945). Vestnik Volgogradskogo gosudarstvennogo universiteta. Seriya 4. Istoriya. Regionovedenie. Mezhdunarodnye otnosheniya [Science Journal of Volgograd State University. History. Area Studies. International Relations], 2021, vol. 26, no. 1, pp. 182-189. (in Russian). DOI: https://doi.org/10.15688/jvolsu4.2021.1.16

УДК 94(47+57)“1941/1945”:355.134

Дата поступления статьи: 21.11.2019

ББК 63.3(2)622-35 Дата принятия статьи: 18.03.2020

\section{НАГРАДНОЕ ПРОИЗВОДСТВО В КРАСНОЙ АРМИИ В ГОДЫ ВЕЛИКОЙ ОТЕЧЕСТВЕННОЙ ВОЙНЫ (1941-1945 ГГ.)}

Дмитрий Викторович Шуняков

Уральский Федеральный университет им. первого Президента России Б.Н. Ельцина, г. Екатеринбург, Российская Федерация

Аннотация. Введение. Анализируется опыт совершенствования системы наградного производства в Красной армии в годы Великой Отечественной войны. Констатируется, что данная структура на момент начала войны было не в состоянии обеспечить массовое награждение военнослужащих. Maтериаль и ме- 
moдbl. При решении поставленных исследовательских задач использовались архивные материалы, опубликованные данные официальной статистики, а также научная литература. Исследование проводилось на основе принципов историзма, объективности и системности. Необходимость обработки количественных данных обусловила использование статистического метода. Результаты. Для обеспечения потребности действующей армии в награждении руководство страны в Вооруженных силах ввело единоначалие и делегировало права награждения непосредственно военному командованию, которое производило награждение на местах и представляло наградные документы через наркомат обороны для утверждения в Президиум Верховного Совета СССР. Отмечается, что для оптимизации наградного производства в частях, соединениях были введены лицевые счета, по которым производилась выдача наградных знаков и документов, а также отчетность по ним. Наградные органы обеспечивали подготовку наградной документации, предоставление ее командующему (командиру) на утверждение, производили награждение отличившихся. Bblводы. Констатируется, что принятые меры по совершенствованию наградного производства приблизили его к участникам боев. Около 90 \% всех награждений было произведено военным командованием. Показано, что награждение военнослужащих привело к росту их профессионального мастерства, повысило личную заинтересованность в результатах боевой деятельности, что явилось одним из факторов победы в войне.

Ключевые слова: СССР, Великая Отечественная война, народный комиссар обороны, Красная армия, наградное производство.

Цитирование. Шуняков Д. В. Наградное производство в Красной армии в годы Великой Отечественной войны (1941-1945 гг.) // Вестник Волгоградского государственного университета. Серия 4, История. Регионоведение. Международные отношения. - 2021. - Т. 26, № 1. - C. 182-189. - DOI: https://doi.org/10.15688/ jvolsu4.2021.1.16

Введение. Наградная система является одним из важнейших государственных атрибутов. Ей сопутствует наградное производство, представляющее собой установленный законодательными актами порядок применения наград различными наградными инстанциями. Если о самих наградах написано достаточно, то деятельности наградных органов уделяется куда меньше внимания. На взгляд автора, это странно, поскольку именно наградное производство определяет эффективность наградной системы.

Методы и материалы. Основной источниковой базой исследования стали материалы, опубликованные в справочнике «Военные кадры Советского государства в Великой Отечественной войне 1941-1945 гг.» под редакцией А.П. Белобородова, документально-историческом очерке «Офицерский корпус и кадровые органы Вооруженных Сил России» под редакцией Н.А. Панкова, в работе В.А. Жилина «Организационное строительство Вооруженных Сил: история и современность», каталогесправочнике Б.В. Айрапетяна «Нагрудные знаки Красной армии (1941-1945 гг.)», а также диссертации С.А. Иванова «Развитие системы награждений орденами и медалями военнослужащих Красной армии: 1918-1945 гг.» [1; 7; $11 ; 13 ; 18]$. В этих работах был исследован процесс усовершенствования наградного производ- ства в годы войны, значение и роль наградной системы в победе над врагом, проанализирована деятельность органов государственного управления и военного командования по совершенствованию наградной системы. Деятельность руководства страны привела к существенному упрощению наградного производства, расширению доступного арсенала наград, что позволило военному командованию по достоинству отмечать заслуги военнослужащих.

Кроме того, автором проанализированы нормативно-правовые документы, хранящиеся в Центральном архиве Министерства обороны РФ, фонд 33 «Главное управление кадров НКО» $[9$, л. 59; 12, л. 172; 14, л. 342; 18, л. 285; 20, л. 266], а также в сборниках документов [5; 6; 22], в частности, постановления, приказы о совершенствовании наградного производства Красной армии, анализа деятельности наградных органов, выявлении недостатков и злоупотреблений в наградной сфеpe, наказания виновных. Анализ этих материалов позволяет сделать вывод о большом внимании руководства страны и военного командования к наградному производству, считавшему его важнейшей составляющей в мотивации военнослужащих на борьбу с врагом. Выявленные факты злоупотреблений должностных лиц, а также недостатков в наградном производстве немедленно пресекались. 
Обращение к мемуарам участников войны позволило от первого лица узнать отношение к деятельности наградных органов по поощрению военнослужащих. Анализ воспоминаний позволяет сделать вывод о большом мотивационном воздействии усовершенствованного наградного производства на военнослужащих [2; $3 ; 8 ; 10 ; 21 ; 23]$.

В основу методологии работы положены общенаучные методы исследования (анализ, синтез, обобщение), а также специальные методы исторического исследования, прежде всего метод системного анализа, что позволило показать процесс усовершенствования наградного производства в общем контексте деятельности органов государственного управления по мобилизации страны на борьбу с врагом.

Обсуждение. Наградное производство Красной армии на момент начала Великой Отечественной войны замыкалось на высшие органы государственной власти. Минимальным войсковым формированием, где имелись наградные органы, являлся полк. В строевой части последнего оформлялись наградные документы и отправлялись в вышестоящие инстанции (строевая часть дивизии, строевое отделение в корпусе, наградное отделение в армии, отдел по присвоению званий Управления кадров РККА, Высшая аттестационная комиссия НКО), где наградной материал согласовывался и отправлялся выше либо отклонялся [11, с. $234 ; 16$, с. 46]. После прохождения многочисленных инстанций согласования документы оказывались в наградной комиссии при Президиуме Верховного Совета СССР, откуда документы отправлялись в Президиум Верховного Совета СССР для издания указа о награждении. Представленный к награждению вызывался в Москву и получал орден или медаль из рук руководителей государства [17].

Многоступенчатое наградное производство мирного времени оказалось абсолютно неприспособленным к условиям крупномасштабных боевых действий начавшейся войны. Из общего количества представленных к награждению во втором полугодии 1941 г. только треть (30,5 \%) смогла получить заслуженные награды [18, л. 285]. В условиях войны оказалось совершенно невозможным обеспечить прибытие в Москву для награждения всех отличившихся. Из-за многочисленных согласовывающих инстанций наградная процедура оказалось слишком затянутой по времени. Например, в отделе кадров Северо-Западного фронта в июле 1942 г. прохождение наградных документов от полка до фронта составляло от 30-40 дней [5, с. 269-271]. Командир роты 565-го отдельного саперного батальона С.А. Данич вспоминал: «В начале войны почти совсем не награждали» [8].

Наградное производство нуждалось в серьезных изменениях, что прекрасно понимало руководство страны, считавшее наградную систему важным стимулом в укреплении боевого духа армии и воодушевления населения. «Получить в такой момент награду, - говорил председатель Президиума Верховного Совета СССР М.И. Калинин в декабре 1941 г., - высокая честь. Это - признание того, что вы активно боретесь с врагом, это... благодарность от советского народа» [15, с. 105].

Для повышения эффективности наградного производства были предприняты радикальные меры. Во-первых, была увеличена наградная база. В дополнение к существовавшим наградам были учреждены 9 орденов (многие из них имели несколько степеней, что по факту давало целых 18), а также 19 медалей [24, с. 30-37].

Во-вторых, в сентябре 1941 г. наградными правами в отношении военнослужащих до командира полка включительно были наделены Военные советы фронтов, а 1 апреля 1942 г. Военные советы отдельных армий $[5$, с. 171 ; 19, с. 118]. Наградное производство было аналогично довоенному с той лишь разницей, что конечной наградной инстанцией являлся штаб фронта (отдельной армии). Военный совет фронта (армии) рассматривал представления, готовил приказ о награждении за подписью командующего фронта (армии) и вручал награды. Протоколы заседаний отправлялись в Москву и утверждались указами Президиума Верховного Совета СССР [7, с. 364-365].

Несмотря на то что время наградного процесса серьезно сократилось, подобный алгоритм не решал проблему в целом и имел ряд серьезных недостатков. Например, из-за того, что наградные документы утверждались сразу в Президиуме Верховного Совета СССР без согласования с Главным управлением кад- 
ров НКО, случались прецеденты двойных награждений [20]. Военные советы не успевали обрабатывать представления к награждению вследствие частой ротации (переподчинения) воинских частей между фронтами и армиями [12].

Разное время прохождения наградного материала до Военных советов фронтов и армий (при награждении военнослужащих до командира полка) и Президиума Верховного совета СССР (в случае награждения высших эшелонов военного командования) приводило к тому, что за одни и те же бои солдаты и младший командный состав уже был награжден орденами и медалями, а старший и высший командный состав еще нет [9].

Необходимость проведения радикальных реформ не вызывала сомнения. Упразднение 9 октября 1942 г. института военных комиссаров сосредоточило наградные полномочия в руках командира, который командовал военнослужащими на поле боя и соответственно объективно оценивал их заслуги в представлении к награждению [22, с. 200-201].

Одновременно с единоначалием командиры воинских формирований были наделены правом награждения подчиненных от имени Президиума Верховного Совета. Наградные права были строго дифференцированы. Так, командир полка (минимальное должностное лицо, наделенное наградными полномочиями) мог награждать медалями только солдат и сержантов. Командир дивизии, кроме солдат и сержантов, уже награждал офицеров до командира роты, а его арсенал награждения был расширен орденами Красной звезды и Славы 3-й степени. Наградные полномочия командующего фронтом, кроме указанных категорий военнослужащих, распространялись и на генералов до командира дивизии. Его арсенал включал все ордена и медали, за исключением высших степеней государственных наград и звания Героя Советского Союза. Право награждения высшими государственными наградами СССР оставил за собой Президиум Верховного Совета [5, с. 360-361, 384-385; 6, c. $74-75,83,87-88,136,203-205,247-248,303]$.

Представление к награждению осуществлялось по вертикали командования снизу вверх. Командир роты (взвода) составлял на отличившегося наградной лист в двух экзем- плярах, содержавший описание боевого отличия, время и место его совершения [7, с. 389]. Командир танка М.Д. Чубарев вспоминает: «В зависимости от того, кто как выполнял свою задачу, так того и отмечали. Определяли это в первую очередь наши непосредственные командиры. Они делали представление к наградам» [23]. Представление к награде составлялось как по конкретному подвигу, так и по совокупности заслуг. «Из частей приходят отзывы, как ты выполнил задачу, - рассказывал командир саперного взвода 3-й штурмовой инженерно-саперной бригады А.Н. Будницкий, - это все подшивалось, а потом награждали, по совокупности» [2].

Второй из наградных листов оставался в штабе части, а первый отправлялся в вышестоящие инстанции, где командиры (начальники) издавали приказ о награждении, либо, в случае превышения их наградных полномочий, ставили свою резолюцию и отправляли дальше по команде. В итоге наградной материал приходил в Главное управление кадров НКО (военнослужащих пехоты и кавалерии), либо в отделение кадров соответствующего управления по роду войск. Начальник управления ставил свою визу и отправлял наградные листы в Президиум Верховного Совета СССР [7, с. 389].

После утверждения награждения, во втором экземпляре, остававшемся в штабе части, ставилась отметка с указанием вида награды и номера, даты приказа о награждении [7, с. 390].

Для достижения максимального морального эффекта от награждения вручение наград производилось с соблюдением торжественного церемониала. Командир танкового взвода 40-й гвардейской танковой бригады Н.Н. Борисов вспоминал: «А вскоре наступило 23-е февраля... Нас заранее предупредили, что состоится общее построение. И на этом митинге был зачитан приказ о награждении, и я получил свою первую награду - орден Красной звезды» [3].

В период Великой Отечественной войны потребность в орденах и медалях оказалось очень высокой, от промышленности было «недополучено» свыше 2,5 млн наградных знаков [7, с. 397]. При их отсутствии выдавалось удостоверение на получение награды позднее по 
месту службы или по месту жительства в военкомате [7, с. 394]. Однако в условиях войны обеспечить четкую выдачу по удостоверениям орденов и медалей оказалось невозможным (удостоверения и выписки терялись, неправильно оформлялись, представленные к награждению погибали, оказывались в госпиталях и т. п.). После окончания войны было установлено, что около 3 млн наград оказались неврученными [4, с. 639].

Документы погибших военнослужащих, а также награжденных посмертно отправлялись в отдел по учету и регистрации награжденных при секретариате Президиума Верховного Совета СССР, а в Главное управление кадров НКО высылались копии [14]. Уже в ходе войны появились исключения. В память о погибшем семьи (родственники) получали ордена Отечественной войны, медали за оборону городов, партизанскую медаль, а также документы [22, с. 355].

В целях минимизации времени наградного процесса в воинских формированиях стали храниться запасы наград в соответствии с «лицевым счетом». Кадровый орган воинского формирования на основании «лицевого счета» производил выдачу наградных знаков и документов, а также отчитывался перед вышестоящими наградными организациями. Ежемесячно комиссионно осуществлялась проверка наличия и движения орденов и медалей, о чем составлялся акт, утверждаемый командованием воинского формирования и представляемый в вышестоящий кадровый орган. По состоянию на первое число каждого месяца в Главное управление кадров НКО отделы кадров фронтов (отдельных армий) представляли отчетность по врученным орденам и медалям на основании полученных данных от кадровых органов входивших в состав фронта (армии) воинских формирований (от полка до корпуса). На награжденных в отделе кадров фронта (армии) оформлялись учетные карточки, в нижестоящих наградных органах - алфавитные книги [7, с. 395-396, 400].

При убытии части из состава армии (фронта) кадровый орган отчитывался за движение наградных знаков, сдавал по акту имеющиеся ордена и медали в вышестоящий кадровый орган, который на лицевом счете делал об этом отметку [7, с. 395-396].
В ходе войны имелись случаи неправомерных награждений рядом должностных лиц. Например, командир 1593-го полка П.А. Щербинко незаконно наградил орденами своих родственников, а старший лейтенант А.А. Кощанов, пользуясь правами помощника начальника штаба, наградил себя двумя орденами Красной звезды [6, с. 299; 7, с. 378]. В целях недопущения случаев злоупотреблений при награждении Президиум Верховного Совета СССР указом от 2 мая 1943 г. ввел уголовную ответственность на срок до трех лет, а за незаконное ношение наград - до одного года [22, с. 148].

Несмотря на очевидные преимущества усовершенствованной системы награждения военнослужащих, имелись и недостатки. Процесс награждения солдата и сержанта орденом занимал неоправданно много времени при прохождении многочисленных наградных инстанций в дивизии (корпусе, армии). Разведчик Н.Д. Доронин вспоминал: «Обычно доходила награда до нас так. Пока она пройдет все эти канцелярские проверки от командира роты до командира полка, а там дальше - еще через дивизию и через корпус, срок ожидания награды на несколько месяцев затягивается. А то и полгода проходит, пока тебя наградят. Даже в иной раз забываешь, что тебя представили к награде» [10]. По этой причине многие солдаты и сержанты предпочитали награждение медалью сейчас, чем ждать орден месяцы, а то и вообще получить отказ от вышестоящей наградной инстанции.

Также наградными правами были обделены командиры отдельных подразделений (батальон, рота). Заместитель командира такого батальона Л.С. Свердлов вспоминал: «Все наградные листы заполненные в ОПАБе (Отдельный пулеметно-артиллерийский батальон. - Д. Ш.) шли напрямую в штаб армии, в составе которой мы находились. В половине случаев эти наградные листы куда-то терялись по дороге, а те наградные, которые попали в штаб, ложились на стол к “канцелярским крысам", самолично решавшим, кому дать боевую награду, а кто “перебьется”» [21].

Всего за годы Великой Отечественной войны было осуществлено около 13 млн награждений орденами и медалями [7, с. 362], при этом 90 \% всех награждений военнослу- 
жащих было произведено приказами военного командования [7, с. 380], из них 64,5 \% приказами командиров полков, то есть непосредственно на поле боя [25, кн. 1, с. 255].

Выводы. В кратчайшие сроки руководству страны удалось кардинально изменить наградное производство Красной армии. Сосредоточение наградных полномочий в руках командиров воинских формирований минимизировало наградной процесс, позволило им объективно оценивать заслуги подчиненных в бою и производить награждение. Между тем архивные источники и воспоминаний участников войны позволяют сделать вывод о недостаточной проработанности механизма награждения самой многочисленной категории военнослужащих - солдат и сержантов. При этом усовершенствованное наградное производство имело большое мотивационное влияние на офицеров и солдат, что способствовало победе в Великой Отечественной войне.

\section{СПИСОК ЛИТЕРАТУРЫ}

1. Айрапетян, Б. В. Нагрудные знаки Красной армии (1941-1945) / Б. В. Айрапетян. - М. : Collector's Book, 2004. - 180 c.

2. Будницкий Александр Наумович // Федеральный портал «Я помню». - Электрон. текстовые дан. - Режим доступа: https://iremember.ru/ memoirs/saperi/budnitskiy-aleksandr-naumovich (дата обращения: 14.11.2019). - Загл. с экрана.

3. Борисов Николай Николаевич (танкист) // Федеральный портал «Я помню». - Электрон. текстовые дан. - Режим доступа: https://iremember.ru/ memoirs/tankisti/borisov-nikolay-nikolaevich (дата обращения: 16.11.2019). - Загл. с экрана.

4. Великая Отечественная война 1941-1945 годов. В 12 т. Т. 1. Основные события войны / гл. ред. комис. ген. армии С. К. Шойгу. - М. : Кучково поле, 2015. $-976 \mathrm{c}$.

5. Великая Отечественная война : Приказы народного комиссара обороны СССР 1941-1942 гг. / под общ. ред. В. А. Золотарева. - М. : Терра, 1997. - T. 13 (2-2). -448 c.

6. Великая Отечественная война : Приказы народного комиссара обороны СССР 1943-1945 гг. / под общ. ред. В. А. Золотарева. - М. : Терра, 1997. - T. 13 (2-3). - 456 c.

7. Военные кадры Советского государства в Великой Отечественной войне 1941-1945 гг. / под общ. ред. генерала армии А. П. Белобородова. М. : Воениздат, 1963. -624 c.
8. Данич Семен Антонович (командир роты 565-го отдельного саперного батальона) // Федеральный портал «Я помню». - Электрон. текстовые дан. - Режим доступа: https://iremember.ru/ memoirs/saperi/danich-semen-antonovich (дата обращения: 16.11.2019). - Загл. с экрана.

9. Докладная записка начальника Главного управления кадров генерал-майора Голикова от 1 июня 1942 г. // Центральный архив Министерства обороны РФ (далее - ЦАМО). - Ф. 33. - Оп. 42576сc. Д. 26. - Л. 59.

10. Доронин Николай Дмитриевич (разведчик) // Федеральный портал «Я помню». - Электрон. текстовые дан. - Режим доступа: https://iremember.ru/ memoirs/razvedchiki/doronin-nikolay-dmitrievich (дата обращения: 15.11.2019). - Загл. с экрана.

11. Жилин, В. А. Организационное строительство Вооруженных Сил : история и современность / В. А. Жилин. - М. : Воентехиздат, 2002. - 584 с.

12. Заявка Волховского фронта на получение наград от 11 февраля 1942 г. // ЦАМО. - Ф. 33. Оп. 42576сс. - Д. 248/2. - Л. 172.

13. Иванов, С. А. Развитие системы награждений орденами и медалями военнослужащих Красной армии (1918-1945 гг.) : дис. ... канд. ист. наук / Иванов Сергей Анатольевич. - М., 2009. - 254 с.

14. Инструкция 4-го отдела ГУК НКО командующим фронтам по учету орденов, медалей и орденских документов, сентябрь 1942 г. // ЦАМО. Ф. 33. - Оп. 42576сc. - Д. 47. - Л. 342.

15. Калинин, М. И. Статьи и речи (1941-1946 гг.) / М. И. Калинин. - М. : Политиздат, 1975. - 671 с.

16. Командный и начальствующий состав Красной армии в 1940-1941 гг. : структура и кадры центрального аппарата НКО СССР, военных округов и общевойсковых армий : документы и материалы / под ред. В. Н. Кузеленкова. - М. ; СПб. : Летний сад, 2005. -272 с.

17. Конституция (Основной закон) СССР в редакции от 5 декабря 1936 г. // Система «Гарант». - Электрон. текстовые дан. - Режим доступа: http:// constitution.garant.ru/history/ussr-rsfsr/1936/red_1936/ 3958676 (дата обращения: 05.11.2019). - Загл. с экрана.

18. Отчет Главного управления кадров НКО за второе полугодие 1941 г. // ЦАМО. - Ф. 33. Оп. 11447. - Д. 38. - Л. 285.

19. Офицерский корпус и кадровые органы Вооруженных Сил России / под ред. Н. А. Панкова. М. : РИЦ ГШ ВС РФ, 2003. - $224 \mathrm{c}$.

20. Письмо начальника Главного управления кадров генерал-майора Румянцева в секретариат Верховного Главнокомандующего 3 апреля 1942 г. // ЦАМО. - Ф. 33. - Оп. 42576сс. - Д. 26. - Л. 66.

21. Свердлов Лев Соломонович // Федеральный портал «Я помню». - Электрон. текстовые дан. Режим доступа: https://iremember.ru/memoirs/saperi/ 
sverdlov-lev-solomonovich (дата обращения: 12.11.2019). - Загл. с экрана.

22. Сборник законов СССР и указов Президиума Верховного Совета СССР: 1938 г. - июль 1956 г. / под ред. канд. юрид. наук Ю. И. Мандельштама. М. : Гос. изд-во юрид. лит., 1956. - 500 с.

23. Чубарев Михаил Дмитриевич (танкист) // Федеральный портал «Я помнинское званиею». Электрон. текстовые дан. - Режим доступа: https:// iremember.ru/memoirs/tankisti/chubarev-mikhaildmitrievich (дата обращения: 14.11.2019). - Загл. с экрана.

24. Шуняков, Д. В. Развитие советской наградной системы и поощрений военнослужащих в 1941-1945 гг. / Д. В. Шуняков // Военно-исторический журнал. - 2018. - № 4. - С. 30-37.

25. Штеменко, С. М. Генеральный штаб в годы войны. В 2 кн. Кн. 2 / С. М. Штеменко. - М. : Воениздат, 1989. -560 c.

\section{REFERENCES}

1. Hayrapetyan B.V. Nagrudnye znaki Krasnoj armii (1941-1945) [Badges of the Red Army (19411945)]. Moscow, Collector's Book Publ., 2004. 180 p.

2. Budnicki Alexander Naumovich. Federal'nyj portal «Ja pomnju» [Federal Portal "I Remember"]. URL: https://iremember.ru/memoirs/saperi/budnitskiyaleksandr-naumovich/ (accessed 14 November 2019).

3. Borisov Nikolai Nikolayevich (tankist) [Borisov Nikolai Nikolayevich (Tank Crew Man)]. Federal'nyj portal «Ja pomnju» [Federal Portal "I Remember"]. URL: https://iremember.ru/memoirs/ tankisti/borisov-nikolay-nikolaevich/ (accessed 16 November 2019).

4. Shoygu S.K., ed. Velikaja Otechestvennaja vojna 1941-1945 godov. V 12 t. T. 1. Osnovnye sobytija vojny [Great Patriotic War of 1941-1945. In 12 Vols. Vol. 1. Main Events of the War]. Moscow, Kuchkovo pole Publ., 2015. 976 p.

5. Zolotaryov V.A., ed. Velikaja Otechestvennaja vojna: Prikazy narodnogo komissara oborony SSSR 1941-1942 gg. [Great Patriotic War. Orders of the People's Commissar of Defense of the USSR of 19411942]. Moscow, Terra Publ., 1997, vol. 13 (2-2). 448 p.

6. Zolotaryov V.A., ed. Velikaja Otechestvennaja vojna: Prikazy narodnogo komissara oborony SSSR 1943-1945 [Great Patriotic War. Orders of the People's Commissar of Defense of the USSR of 1943-1945]. Moscow, Terra Publ., 1997, vol. 13 (2-3). 456 p.

7. Beloborodov A.P., ed. Voennye kadry Sovetskogo gosudarstva $v$ Velikoj Otechestvennoj vojne 1941-1945 gg. [Military Personnel of the Soviet State in the Great Patriotic War of 1941-1945]. Moscow, Voenizdat, 1963. 624 p.
8. Danich Semen Antonovich (komandir roty 565-go otdel'nogo sapernogo batal'ona) [Danich Semen Antonovich (Company Commander of the $565^{\text {th }}$ Separate Demining Battalion]. Federal'nyj portal «Ja pomnju» [Federal Portal "I Remember"]. URL: https://iremember.ru/memoirs/saperi/danich-semenantonovich/ (accessed 16 November 2019).

9. Dokladnaja zapiska nachal'nika Glavnogo upravlenija kadrov general-majora Golikova ot 1 ijunja 1942 g. [Report from Major General Golikov, Shief of Personnel Department, June 1, 1942]. Central'nyj arhiv Ministerstva oborony RF (TsAMO) [Central Archive of the Ministry of Defense of the Russian Federation], f. 33, inv. 42576ss, d. 26, 1. 59.

10. Doronin Nikolai Dmitrievich (razvedchik) [Doronin Nikolai Dmitrievich (Intelligence Officer)]. Federal'nyj portal «Ja pomnju» [Federal Portal "I Remember"]. URL: https://iremember.ru/memoirs/ razvedchiki/doronin-nikolay-dmitrievich/ (accessed 15 November 2019).

11. Zhilin V.A. Organizacionnoe stroitel'stvo Vooruzhennyh Sil: istorija i sovremennost' [Organizational Construction of the Armed Forces: History and Modernity]. Moscow, Voentekhizdat, 2002. $584 \mathrm{p}$.

12. Zajavka Volhovskogo fronta na poluchenie nagrad ot 11 fevralja $1942 \mathrm{~g}$. [Application of the Volkhov Front for Awards Dated February 11, 1942]. TsAMO [Central Archive of the Ministry of Defense of the Russian Federation], f. 33, inv. 42576ss, d. 248/2, 1. 172.

13. Ivanov S.A. Razvitie sistemy nagrazhdenij ordenami $i$ medaljami voennosluzhaschih Krasnoj armii (1918-1945 gg.): dis. ... kand. ist. nauk [The Development of the System of Awarding Military Personnel of the Red Army with Orders and Medals (1918-1945). Cand. hist. sci. diss.]. Moscow, 2009. 254 p.

14. Instrukcija 4-go otdela GUK NKO komandujushhim frontam po uchetu ordenov, medalej i ordenskih dokumentov, sentjabr' 1942 g. [Instruction of the $4^{\text {th }}$ Department of the Main Personnel Directorate of the People's Commissariat of Defense to the Commanders of Fronts on Accounting of Orders, Medals and Order Documents, September 1942]. $T_{S A M O}$ [Central Archive of the Ministry of Defense of the Russian Federation], f. 33, inv. 42576ss, d. 47, 1. 342.

15. Kalinin M.I. Stat'i i rechi (1941-1946 gg.) [Articles and Speeches (1941-1946)]. Moscow, Politizdat, 1975.671 p.

16. Kuzelenkov V.N., ed. Komandnyj $i$ nachal'stvujushhij sostav Krasnoj armii v 19401941 gg.: struktura i kadry central'nogo apparata NKO SSSR, voennyh okrugov $i$ obshhevojskovyh armij: dokumenty $i$ materialy [Command Staff of the Red Army in 1940-1941: Structure and Personnel of the Central Apparatus of the People's Commissariat of Defense of the USSR, Military Districts and General 
Military Armies: Documents and Materials]. Moscow, Saint Peterburg, Letniy sad Publ., 2005. 272 p.

17. Konstitucija (Osnovnoj zakon) SSSR v redakcii ot 5 dekabrja $1936 \mathrm{~g}$. [Constitution (Basic Law) of the USSR as Amended on December 5, 1936]. Access from "Garant" informational and legal web portal. URL: http://constitution.garant.ru/history/ussr-rsfsr/1936/ red_1936/3958676/ (accessed 5 November 2019).

18. Otchet Glavnogo upravlenija kadrov NKO za vtoroe polugodie 1941 g. [Report of the General Personnel Department of the People's Commissariat of Defense for the Second Half of 1941]. Ts $A M O$ [Central Archive of the Ministry of Defense of the Russian Federation], f. 33, inv. 11447, d. 38, 1. 285.

19. Pankov N.A., ed. Oficerskij korpus i kadrovye organy Vooruzhjonnyh Sil Rossii [Officer Corps and Personnel Bodies of the Russian Armed Forces]. Moscow, RITs GSh VS RF, 2003. 224 p.

20. Pis'mo nachal'nika Glavnogo upravlenija kadrov general-majora Rumjanceva $\mathrm{v}$ sekretariat Verhovnogo Glavnokomandujushhego 3 aprelja 1942 g. [Letter from Major General Rumyantsev, Shief of Personnel Department, to the Secretariat of the Supreme Commander-in-Chief, 3 April 1942]. Ts AMO [Central Archive of the Ministry of Defense of the Russian Federation], f. 33, inv. 42576ss, d. 26, 1. 66.
21. Sverdlov Leo Solomonovich. Federal'nyj portal «Ja pomnju» [Federal Portal "I Remember”]. URL: https://iremember.ru/memoirs/saperi/sverdlovlev-solomonovich/ (accessed 12 November 2019).

22. Mandelstam Yu.I., ed. Sbornik zakonov SSSR i ukazov Prezidiuma Verhovnogo Soveta SSSR: 1938 g. - ijul' 1956 g. [Collection of Laws of the USSR and Decrees of the Presidium of the Supreme Soviet of the USSR: 1938 - July 1956]. Moscow, Gosudarstvennoe izd-vo yuridicheskoy literatury, 1956. $500 \mathrm{p}$.

23. Chubarev Mikhail Dmitrievich (tankist) [Chubarev Mikhail Dmitrievich (Tank Crew Man)]. Federal'nyj portal «Ja pomnju» [Federal Portal "I Remember"]. URL: https://iremember.ru/memoirs/ tankisti/chubarev-mikhail-dmitrievich/ (accessed 14 November 2019).

24. Shunyakov D.V. Razvitie sovetskoj nagradnoj sistemy i pooshhrenij voennosluzhashhih v 19411945 gg. [Development of the Soviet Award System and Incentives of Military Personnel in 1941-1945]. Voenno-istoricheskij zhurnal [Military History Journal], 2018, no. 4, pp. 30-37.

25. Stemenko S.M. General'nyj shtab v gody vojny. $V 2$ kn. Kn. 2 [General Staff During the War. In 2 Vols. Vol. 2]. Moscow, Voenizdat, 1989. 560 p.

\section{Information About the Author}

Dmitry V. Shunyakov, Candidate of Sciences (History), Associate Professor, Military Training Center, Ural Federal University named after the first President of Russia B.N. Yeltsin, Mira St, 19, 620002 Yekaterinburg, Russian Federation, konigsberg039@mail.ru, https://orcid.org/0000-0003-2649-4179

\section{Информация об авторе}

Дмитрий Викторович Шуняков, кандидат исторических наук, доцент военного учебного центра, Уральский Федеральный университет им. первого Президента России Б.Н. Ельцина, ул. Мира, 19, 620002 г. Екатеринбург, Российская Федерация, konigsberg039@mail.ru, https://orcid.org/0000-0003-2649-4179 